\title{
Politique
}

\section{Note aux lecteurs et aux lectrices de la Revue}

\section{Réjean Pelletier}

Numéro 23, hiver 1993

Tendances de la science politique au Québec

URI : https://id.erudit.org/iderudit/019568ar

DOI : https://doi.org/10.7202/019568ar

Aller au sommaire du numéro

Éditeur(s)

Société québécoise de science politique

ISSN

0711-608X (imprimé)

1918-6584 (numérique)

Découvrir la revue

Citer ce document

Pelletier, R. (1993). Note aux lecteurs et aux lectrices de la Revue. Politique, (23),

5-5. https://doi.org/10.7202/019568ar d'utilisation que vous pouvez consulter en ligne.

https://apropos.erudit.org/fr/usagers/politique-dutilisation/ 


\section{NOTE AUX LECTEURS ET AUX LECTRICES DE LAREVUE}

À la suite d'une proposition du Conseil de rédaction de la revue, entérinée par le Conseil d'administration de la Société québécoise de science politique, Politique est devenu officiellement avec le numéro 22 la Revue québécoise de science politique.

Ce nouveau nom vient clarifier celui qui était utilisé dans les derniers numéros et qui, faisant appel à l'un et à l'autre nom, soulevait une certaine confusion aussi bien auprès des auteurs et auteures que des lecteurs et lectrices. Surtout, il établit plus clairement que la revue, propriété de la Société québécoise de science politique, se veut l'organe scientifique de la communauté des politologues du Québec et de l'extérieur.

Je voudrais également rappeler que la revue accueille des articles en français et en anglais en provenance non seulement du Québec, mais aussi de l'ensemble du Canada et de l'étranger. Lorsqu'un article de langue anglaise est accepté pour publication, il est traduit en français, en conformité avec les politiques de la revue.

Le Directeur 